\title{
DESLOCAMENTOS, INVENÇÃO E FORMAÇÃO OUTRA - EM COMPANHIA DE FOUCAULT
}

\author{
DISPLACEMENTS, INVENTION AND INNOVATIVE TEACHINGS - IN FOUCAULT'S COMPANY
}

DESPLAZAMIENTOS, INVENCIÓN Y FORMACIÓN INNOVADORA - EN COMPAÑÍA DE FOUCAULT

\author{
DIAS, Rosimeri de Oliveira1 \\ RODRIGUES, Heliana de Barros Conde ${ }^{2}$
}

\section{RESUMO}

O artigo expõe análises de pesquisas-intervenção realizadas com formação de professores na Universidade do Estado do Rio de Janeiro. Cartografa movimentos que nos desprendem dos exercícios de poder, servindo de reveladores para transformações do sujeito. Lança mão de três dispositivos: as linhas tecidas no dispositivo aula, recorrendo ao curso A Hermenêutica do Sujeito e à noção de arqueologia; as linhas que se delineiam na atualidade mediante entrevistas de Foucault e escritos de seus intercessores; e as estratégias singulares de formação que privilegiam práticas ético-políticas regulares e trabalhos dotados de continuidade, embora sem efeitos de coerção.

Palavras chave: Deslocamentos. Formação inventiva de professores. Pesquisa - intervenção. Michel Foucault.

\section{ABSTRACT}

This text presents an analysis of research-interventions carried out in teaching as a major at Universidade do Estado do Rio de Janeiro. Cartography movements that detach us from power exercises, and work as revelers of subjects' transformations. Three devices are presented: Linked lines in the "classroom device", based on The Hermeneutics of Subject and the an archaeological notion; the lines of the device that are outlined by interviews and some text from Foucault's mediators; and the unique strategies of training teachers that privilege ethical practices, regular policies and continuous work, although without the effects of coercion.

Keywords: Displacement. Innovative teachers' improvement. Research - intervention. Michel Foucault.

\section{RESUMEN}

Este texto expone análisis de investigaciones-intervenciones realizadas en la carrera de profesores en la Universidade do Estado do Rio de Janeiro. Cartografía de movimientos que nos desprenden de ejercicios de poder, que ayuda como reveladores para las transformaciones de los sujetos. Se presentan tres dispositivos: las líneas entrelazadas en el "dispositivo clase", con base en el curso de La Hermenéutica del Sujeto y en la noción arqueológica; las líneas del dispositivo que se perfilan por medio de entrevistas y de algunos escritos de mediadores de Foucault; y las estrategias singulares de formar profesores que privilegian prácticas éticas, políticas regulares y trabajo continuo, aunque sin efectos de coerción.

Palabras clave: Desplazamientos. Formación inventiva de profesores. Investigación-intervención. Michel Foucault.

\footnotetext{
1 Universidade do Estado do Rio de Janeiro - UERJ - Brasil.

2 Universidade do Estado do Rio de Janeiro - UERJ - Brasil.
} 


\section{INTRODUÇÃO}

A escolarização continua a ser apontada como a via régia de todas as salvações sociais. Neste panorama, os formadores - professores e professoras - são os agentes mais visados pelos investimentos discursivos e institucionais. Formar melhor os formadores seria, alega-se, a salvação elevada ao quadrado, visto que a forma até hoje assumida tem redundado em fracasso. Professoras de uma universidade pública, ligadas aos cursos de Pedagogia e de Psicologia, respectivamente, defrontamo-nos com uma encomenda explícita ou um encargo generalizado de contribuir com tal "missão" formativa.

O presente escrito refere-se à maneira como temos lidado com tal pedido. Sem recusá-lo a priori, procuramos analisá-lo com o auxílio de alguns autores, Michel Foucault em especial, que consideramos companheiros na tarefa de promover deslocamentos - quer no que tange à "escolasalvação", quer no que remete à "salvação da escola". Não repudiamos o tema da formação; mas a divisamos como uma formação outra, que requer, para efetivar-se, pensamento e invenção.

Aquilo que nos acontece em um modo de vida que se dá entre formação e universidade é o fio condutor dos traçados existenciais relativos a esse problema: o de uma formação que possa ser acatada, mas jamais entendida como salvacionista - deslocada, pois, dos caminhos em que os especialistas a têm situado. Para apreender os traçados existenciais a que nos referimos são necessários dispositivos (FOUCAULT, 2008; DELEUZE, 2016) que façam ver e falar a constituição de uma formação perspectivada pela invenção; ou melhor, a produção de uma política que una conhecer, fazer e viver.

Adotando o princípio cartográfico (DELEUZE; GUATTARI, 2004a) - ato político-investigativo em que se parte das forças e dos processos, jamais das formas resultantes -, este texto busca tecer algumas das análises que temos feito, em pesquisas-intervenção realizadas com formação (de professores e psicólogos), com os estudos foucaultianos que as atravessam, na Universidade do Estado do Rio de Janeiro.

Pensamos a formação justamente pela possibilidade de deslocamento quanto aos lugares acostumados à "dimensão especialista" (DIAS, 2011) - a que diz o que o outro deve fazer e possui um fim antecipadamente dado. O que colocamos em análise são as políticas que atravessam este modo específico de habitar universidade e formação. Para tanto, acompanhamos processos (PASSOS; KASTRUP; ESCÓSSIA, 2009) mediante uma ininterrupta problematização.

No presente artigo, trazemos à cena dispositivos que, compostos por linhas que traçamos neste entrelugar - universidade e formação -, nos forçam a pensar. Para sair do lugar naturalizado da formação, temos colocado nossa atenção no presente vivo e intenso, procurando fazer ver e falar o que nos acontece. Em termos simples, trata-se de estabelecer (e estar atento a) uma relação de habitar o território, de se encontrar, estudar e conversar (DIAS, 2012b).

O ensaio, diz Michel Foucault (1994a), é uma experiência modificadora de si. Ensaiamos, pois, práticas de estar e de fazer/fazer-se nos espaços formativos, de cunho não necessariamente conceitual, teórico ou funcional, porém, tão ou mais frequentemente, ético, estético e político. Foucault 
estava ciente da força desse modo de analisar e intervir, que dá o tom de uma aposta de formação via deslocamentos:

\begin{abstract}
Meu problema ou a única possibilidade de trabalho teórico que me anima seria deixar [...] o vestígio dos movimentos devido aos quais não estou mais no lugar em que estava há pouco. Donde, vamos dizer, essa perpétua necessidade [...] de fazer de certo modo o levantamento dos pontos de passagem em que cada deslocamento pode vir [...] a modificar, se não o conjunto da curva, pelo menos a maneira como podemos lê-la e podemos apreendê-la no que ela pode ter de inteligível. Esse levantamento, por conseguinte, nunca deve ser lido como o plano de um edifício permanente. [...] Trata-se [...] de um traçado de deslocamento, isto é, não de um traçado de edifício teórico, mas do deslocamento pelo qual minhas posições teóricas não param de mudar. (FOUCAULT, 2014a, p. 70-71). (grifos nossos).
\end{abstract}

Os traçados foucaultianos nos têm ajudado a pensar/fazer formação pelo que se move/nos move para forjar transformações no presente. Em especial, visamos a cartografar movimentos que nos desprendam dos exercícios de poder, servindo de reveladores para as transformações do sujeito. Tal questão se distribui pelo que Foucault chama de tríptico, como podemos ver na primeira aula do curso O governo de si e dos outros, de 1983: "o que procurei fazer foi uma história do pensamento. E por 'pensamento' queria dizer o que se poderia chamar de focos de experiência, nos quais se articulam uns sobre os outros: primeiro, as formas de um saber possível; segundo, as matrizes normativas de comportamento para os indivíduos; e enfim os modos de existência virtuais para sujeitos possíveis." (FOUCAULT, 2010, p.4).

A fim de desdobrar essa proposta, cumpre voltar a nossa aposta para pensar a formação, ou seja, a do deslocamento. Foucault (2014a) nos sugere, nesse intuito, a prática da anarqueologia, concebendo-a como atitude teórico-prática que suspende os exercícios de poder, possibilitando uma aproximação ao mundo social, ao modo de ser do sujeito e ao pensamento sem que estes, como é comum em outras abordagens, se vejam tomados por garantidos. Nessas abordagens que Foucault almeja descartar, supostos universais - conhecimentos, instituições, modos de subjetivação etc. emergem naturalizados na forma de transcendências explicativas, em lugar de se oferecerem como contingências explicáveis por determinados modos, sempre singulares, de exercício do poder. Sobre o contraste entre o pequeno procedimento anarqueológico que propõe e as grandes manobras filosóficas, assinala Foucault (2014a): "Digamos que se o grande procedimento filosófico consiste em estabelecer uma dúvida metódica que suspende todas as certezas, o pequeno procedimento lateral e na contramão que proponho [...] consiste em fazer intervir sistematicamente não a suspensão de todas as certezas, [...] mas a não-necessidade de todo poder, qualquer que seja". (p. 72)

A anarqueologia problematiza os universais: práticas de qualquer espécie - as de formação nos interessam em especial - estão afetadas de uma não necessidade essencial, de um caráter de matéria bruta sempre passível de transformação. Trata-se, nessa perspectiva, de evitar partir de posições naturalizadas, dizendo "eis o que é a formação", "eis a natureza da formação", "eis o que pode libertar a formação". A tais posições, tão fortemente associadas que formam uma série (categoria universalposição humanista-análise ideológica), Foucault (2014a) contrapõe outra série, que ele defende e chama de "recusa dos universais-posição anti-humanista-análise tecnológica dos mecanismos de poder" (p.74). 
Com o auxílio de tais procedimentos metodológicos - melhor dizendo, contra-metodológicos³-, retornaremos, a partir de agora, à noção de deslocamento. Nessa direção usaremos, em primeiro lugar, as linhas tecidas no dispositivo aula - especificamente, uma das que integram o curso $A$ Hermenêutica do Sujeito (FOUCAULT, 2004a) -, o que nos possibilitará colocar em análise a tessitura da anarqueologia como atitude prática para pensar/fazer uma formação que se desvincule de pedagogias capacitadoras. Em seguida, usaremos linhas do dispositivo delimitado por meio de entrevistas (FOUCAULT, 1994b; 2014b; 2004b) e de escritos de intercessores de Foucault (DELEUZE, 2003; 2016; CHEVALLIER, 2015) para indagar se a formação perspectivada pela invenção pode ser uma formação outra, problematizadora. Em um terceiro momento, daremos a ver estratégias singulares de formar professores, as quais privilegiam práticas éticas e políticas que envolvem trabalhos dotados de continuidade, porém sem efeitos de coerção.

\section{DISPOSITIVO 1: A AULA}

Na primeira hora da aula ministrada em 10 de fevereiro de 1982, Foucault (2004a) se propõe a explicitar uma dupla desvinculação do cuidado de si, ocorrida no período helenístico-romano. Doravante, o cuidado de si deixa de ser, como anteriormente, um preceito complementar ou substitutivo da pedagogia preexistente, na forma de uma relação singular entre mestre e discípulo imposto ao jovem no momento em que este vai entrar na vida adulta - preceito situado num certo tempo e restrito àqueles que, por seu estatuto, detêm a possibilidade de governar os demais -, para tornar-se uma injunção válida para todo o desenrolar da existência e, em certa medida, para todos.

O cuidado de si, a partir de então, é coextensivo à vida e a desvinculação da pedagogia e expressa-se no seu entrelaçamento com "toda uma rede de relações sociais diversas" (FOUCAULT, 2004a, p.254) - organizações escolares, ação de conselheiros privados, relações familiares, de proteção, de amizade etc. -, em acréscimo às relações estritas de mestria. Já a desvinculação da atividade política aparece no afastamento do caráter instrumental que até certo momento - figurado pelo diálogo platônico Alcibíades - cercava o cuidado de si. Se, antes, estar atento a si tinha como objetivo ocupar-se bem com os outros e com a cidade, agora esse cuidado se mostra autofinalizado: "é preciso ocupar-se consigo para si mesmo, de maneira que a relação com os outros seja deduzida, implicada na relação que se estabelece de si para consigo" (FOUCAULT, 2004a, p.254).

Sintetizando as duas desvinculações, emerge a imagem da volta para si mesmo: "é preciso, durante toda a vida, voltar a atenção, os olhos, o espírito, o ser por inteiro enfim, na direção de nós mesmos" (FOUCAULT, 2004a, p.254). Neste ponto, a aula convida a que nos voltemos para o presente. Porque Foucault, sem deixar de mencionar a importância religiosa, notadamente cristã, dessa conversão (a si), nos adverte de seu relevo filosófico, moral e, em particular, político: "Parece-me [...] que não se pode compreender o que foi, ao longo do século XIX, a prática revolucionária, o que foi

\footnotetext{
${ }^{3}$ Foucault (2014a, p. 73) recomenda aos ouvintes do curso Do governo dos vivos, datado de 1980, a leitura de Contra o método, de Paul Feyerabend, então recém-editado na França. Para a edição brasileira, ver FEYERABEND, 1977.
} 
o indivíduo revolucionário e o que foi para ele a experiência da revolução, se não se levar em conta a noção, o esquema fundamental da conversão à revolução”. (FOUCAULT, 2004a, p. 256)

Em tempos, os nossos, em que tanto se alegam decepções com a política, a proposta foucaultiana, que conclama a analisar de que forma uma tecnologia de si tão antiga como a conversão se vinculou a um domínio tão novo como era, no século XIX, a política revolucionária, soa provocadora, porque capaz de nos advertir do caráter inesgotável, e com frequência inesperado, das transformações nos modos de subjetivação. Foucault, todavia, igualmente contempla nossos receios atuais, ao acrescentar:

\footnotetext{
Seria preciso examinar também de que modo esta noção de conversão foi pouco a pouco sendo validada - depois absorvida, depois enxugada e enfim anulada - pela própria existência de um partido revolucionário. $\mathrm{E}$ de que modo passamos do pertencimento à revolução pelo esquema de conversão ao pertencimento à revolução pela adesão a um partido. Sabemos que hoje em dia [...] só nos convertemos à renúncia da revolução. (FOUCAULT, 2004a, p. 257).
}

Ao concluir esta parte da aula com a frase "haveria aí toda uma história a ser feita", Foucault (2004a, p. 257) nos desafia com uma sutil ambiguidade: pois essa história não é somente a da reconstrução discursiva de acontecimentos pretéritos, apontando à importância da conversão na elaboração, presente e futura, de práticas de resistência ao poder político que não se vejam anuladas pela adesão a instâncias de cooptação e burocratização.

Retornando ao momento helenístico-romano, Foucault (2004a) diferencia o tema da conversão então vigente da epistrophé platônica, comandada por uma oposição fundamental entre este mundo o das aparências - e o outro - o das essências. No tipo de conversão que encontramos na prática de si helenístico-romana, o retorno a si deve fazer-se segundo outro eixo, na imanência do mundo, mediante um deslocamento "do que não depende de nós ao que depende de nós" (p. 258). Em franco contraste com a epistrophé platônica, não se trata de uma liberação da alma em relação ao corpo, mas de uma adequação de si para consigo, na qual o conhecimento, cumpre frisar, possui papel menos decisivo: "bem mais do que o conhecimento, será o exercício, a prática, o treinamento, a áskesis, que constituirá o elemento essencial". (FOUCAULT, 2004a, p. 259).

Encerrando a primeira hora, Foucault distingue a conversão helenístico-romana da encontrada na cultura cristã de tipo monástico. No primeiro caso, a conversão a si não implica, como no último, uma ruptura - na cultura cristã dos séculos III e IV d.c.,"o eu que se converte é um eu que renunciou a si mesmo". (FOUCAULT, 2004a, p. 260). Se existe uma ruptura na conversão helenístico-romana, ela se dá quanto a tudo aquilo que cerca o eu, pois, como afirma Foucault (2004a) citando Sêneca, "a filosofia faz com que o sujeito [...] execute o gesto pelo qual, tradicional e juridicamente, o mestre liberta seu escravo" (p. 261).

Voltar-se sobre si mesmo, girar sobre si mesmo, constituem "relações de si para consigo que podem ter a forma de atos. Por exemplo: protege-se, defende-se, arma-se, equipa-se o eu" (p.263). Mas o que significa desviar o olhar das coisas do mundo para conduzi-lo a si? - questão complexa, que será desenvolvida na segunda hora da aula. Foucault, então, acentua a perspectiva de Pierre Hadot 
(2014), para quem a filosofia antiga é "um convite para cada homem transformar a si mesmo" (p. 214). Nesse sentido, indaga: poderíamos considerar o caráter assumido pelas escolas filosóficas do período helenístico-romano, que propõem desviar o olhar das coisas do mundo para dirigi-lo a si, como um prenúncio da importância maior adquirida pelos saberes sobre o homem, quando comparados aos saberes sobre o mundo e a natureza? Novamente se percebe a importância de tais questões para a abordagem contemporânea do tema da formação, quando muito se discute quais conhecimentos seriam indispensáveis a um "professor bem formado".

$\mathrm{Na}$ aula em pauta, Foucault (2004a) focaliza o modo como esse problema é discutido entre os cínicos e entre os epicuristas. No que tange aos primeiros, recorre a um texto de Demetrius no qual vê emergir o que poderia constituir um "critério de utilidade": nele se tem a impressão "de uma divisão no conteúdo mesmo dos conhecimentos, entre conhecimentos inúteis, que poderiam ser os do mundo exterior, [...] e conhecimentos úteis, que tangenciam diretamente a existência humana" (p.284). Apreciemos com mais vagar, porém, a maneira como Demetrius distingue o que merece do que não merece ser conhecido.

O texto do filósofo cínico é composto por duas listas que remetem, respectivamente, ao que é inútil e ao que é útil conhecer. No primeiro caso, diz Foucault (2004a), "temos a causa dos maremotos, a causa do ritmo dos sete anos que cadenciariam a vida humana, a causa das ilusões de ótica, o motivo de haver gêmeos e o paradoxo de duas existências diferentes e nascidas sob o mesmo signo, etc." (p. 285)

Foucault (2004a) não vê os conhecimentos incluídos nessa lista como relativos a coisas pertencentes a um mundo distante e que, consequentemente, não afetariam a existência humana. Modifica, portanto, sua hipótese inicial quanto ao caráter comum daquilo que é julgado inútil por Demetrius:

\footnotetext{
O traço comum e que as tornará inúteis é que se trata [...] de conhecimentos pelas causas [...]. Estão ocultas porque é inútil conhecê-las [...] não porque proibido, mas porque [...], ao conhecêlas não obteremos mais do que algo suplementar, [...] a título de distração e para sentir um prazer que reside, precisa e unicamente na própria descoberta [...]. Prazer de cultura, por consequência, prazer suplementar, prazer inútil e ornamental. (p. 286-287).
}

O que seria útil, então, conhecer? Assim sintetiza Foucault (2004a) a lista de Demetrius: "Que há pouco a temer dos homens, nada a temer dos deuses, que a morte não produz nenhum mal, que é fácil achar o caminho da virtude, que é preciso considerar-se como um ser social nascido para a comunidade." (p. 287)

Essa enumeração em nada se aproxima do que a espiritualidade cristã virá a denominar "segredos da consciência" (arcana conscientiae). Tampouco requer um exame de consciência para ser estabelecida. Não há inventário de um mundo de desejos e paixões; inexiste teoria da alma ou da natureza humana. No plano do conteúdo, segue-se falando dos deuses, do mundo, dos outros homens. Não se reivindica desviar o olhar da natureza para voltá-lo para si mesmo, para a consciência ou para as profundezas da alma. 
Já que se trata, "somente e sempre, do mundo, [...], somente e sempre, dos outros, [...] somente e sempre, do que nos cerca" (FOUCAULT, 2004a, p. 287-288), o que define, afinal, a utilidade desses conhecimentos? Enquanto os conhecimentos inúteis são, como vimos, uma certa modalidade de saber - "pelas causas" -, os úteis seguiriam um modo de saber que Foucault propõe chamar de relacional. "o que há que se ter em conta quando consideramos os deuses, os outros homens, o kósmos, o mundo etc. é a relação entre, por um lado, os deuses, os homens, o mundo, as coisas do mundo, e, por outro, nós" (p. 288).

Esse saber tem a propriedade de ser imediatamente transcritivel em prescrições. No dizer de Foucault (2004a), os conhecimentos úteis constituem "constatações prescritivas" (p. 288), isto é, neles, "o que há a conhecer, ou melhor, a maneira como se há de conhecer é tal que o que é dado como verdade seja lido, de saída e imediatamente, como preceito". (p.289)

Por fim, uma vez adquiridos esses conhecimentos, o modo de ser do sujeito se vê transformado. A hipótese de que o conteúdo seja o elemento definidor da utilidade de um conhecimento é, desse modo, definitivamente descartada.

\begin{abstract}
Os conhecimentos [...] inúteis [...] não se definem pelo conteúdo. Definem-se por um modo de conhecimento causal, com dupla propriedade, ou melhor, com dupla falta [...]: são conhecimentos que não podem transformar-se em prescrições, que não têm pertinência prescritiva; em segundo lugar, que, quando os possuímos, não têm efeito sobre o modo de ser do sujeito. Em contrapartida, será validado um modo de conhecimento que, considerando todas as coisas do mundo [...] relativamente a nós, de pronto poderemos transcrever em prescrições, e elas modificarão o que somos, modificarão o estado do sujeito que as conhece. (FOUCAULT, 2004a, p.289).
\end{abstract}

Com base em Plutarco, Foucault (2004a) opta por dizer determinante da utilidade, ou não, o caráter "etopoético" (p. 290), ou não, do saber e, sem demora, passa à leitura de alguns textos epicuristas, nos quais identifica uma noção ligada ao modo de funcionamento etopoético, a physiología. Para caracterizá-la, acompanha Epicuro, nas Sentenças Vaticanas: "O estudo da natureza (physiologia) não forma fanfarrões nem artistas do verbo, nem pessoas que ostentam uma cultura julgada inviável para as massas, mas homens altivos e independentes, que se orgulham de seus próprios bens, não dos que advêm das circunstâncias" (citado por FOUCAULT, 2004a, p.291).

Segundo Epicuro, tudo o que a physiologia não é caracteriza a paideía, um saber de jactância, uma cultura elaborada por "artistas do verbo"; melhor dizendo, artistas da palavra entendida como ruído (e não como lógos), cuja única meta é "fazer-se admirar pelas massas" (FOUCAULT, 2004a, p.292). Em oposição à paideía, a physiologia equipa (paraskeuázel) homens que não temem, que se dotam da coragem que Ihes permite afrontar os perigos da vida e as autoridades. Esses homens são independentes (autarkeîs), de nada necessitam além de si próprios e, ao reconhecerem a partilha entre o que deles depende e o que deles não depende, estabelecem domínio absoluto quanto ao primeiro aspecto.

Para quem se interessa hoje pelas práticas de formação, como não ver na distinção estabelecida por Epicuro entre physiologia e paideía, embora com o cuidado de evitar anacronismos, um equipamento (paraskeue) extremamente útil para avaliar o que efetivamente importa? Pois a 
paraskeué, nos diz Foucault (2004a), é "a equipagem, a preparação [...] pela qual o sujeito e a alma estarão armados como convém, de maneira necessária e suficiente, para todas as circunstâncias possíveis da vida com que viermos a nos deparar" (p. 293). O resto, concluímos, é mero ruído elitista.

\section{DISPOSITIVO 2: FORMAÇÃO PERSPECTIVADA PELA INVENÇÃO}

Em uma entrevista a Trombadori, datada de 1978, Foucault (1994b) aborda a questão da experiência. Diz então que seus livros foram provocados por experiências; que os próprios livros são experiências; e que uma experiência é aquilo "de que se sai transformado". Para o filósofo, o problema principal não reside em trazer à luz "a significação da experiência quotidiana para reencontrar, no que sou, o sujeito fundador"; ao contrário, a experiência tem por função "arrancar o sujeito de si mesmo" ( $p$. 43).

A entrevista acima citada, algumas outras presentes em Ditos e Escritos e textos de intercessores de Foucault tomam os fios soltos deste momento, deles fazendo mais um dispositivo para indagar em que medida conseguimos manter vivo, na formação, um campo problemático princípio para uma formação inventiva de professores (DIAS, 2012a).

Vale considerar, nesse sentido, o que nos diz Deleuze (2016) acerca das consequências do pensar por dispositivos: o "repúdio dos universais" e a "mudança de orientação, que se desvia do Eterno para apreender o novo" (p. 363-364). "Pertencemos a dispositivos e neles agimos" (p.365), afirma em seguida, pois o que emerge do encontro com o que ainda não está delineado é a diferença. Daí não ser possível antecipar uma experiência, apenas estar atento aos acontecimentos e singularidades.

Deleuze (2016) também acentua que para apreender a obra de Foucault não é possível deixar de fora as entrevistas, pois enquanto nos livros ele nos fala sobretudo de "linhas de sedimentação" ou "estratificação", nas entrevistas traça "linhas de atualização" ou "criatividade", diagnósticos que nos empurram "para um porvir, para um devir" (p. 367-368). Conduzidas por essas palavras, insistimos: mais importante do que pensar é o que nos força a pensar - frase com que Deleuze (2003) reafirma a potência da problematização.

Em entrevista concedida em 1983 a Dreyfus e Rabinow, Foucault (2014b) busca esclarecer o que vem a ser seu retorno aos gregos, pondo ênfase juatamente na problematização:

\footnotetext{
Penso que o trabalho que se deve fazer é um trabalho de problematização e de perpétua reproblematização. O que bloqueia o pensamento é admitir implícita ou explicitamente uma forma de problematização e buscar uma solução que possa substituir-se àquela que se aceita. Ora, se o trabalho do pensamento tem um sentido - diferente daquele que consiste em reformar as instituições e os códigos - é retomar na raiz a maneira como os homens problematizam seu comportamento (sua atividade sexual, sua prática punitiva, sua atitude quanto à loucura etc.). (p. 217).
} 
Em seguida, ressalta o valor do trabalho do pensamento, desde que não o essencializemos:

[...] o pensamento não é o que nos faz crer no que pensamos nem admitir o que nós fazemos; mas o que nos faz problematizar até o que nós somos nós mesmos. O trabalho do pensamento não é denunciar o mal que habitaria secretamente em tudo o que existe, mas pressentir o perigo que ameaça em tudo o que é habitual e tornar problemático tudo o que é sólido. (FOUCAULT, 2014b, p. 217).

Seguimos com outra entrevista, de 1984, no decorrer da qual Rabinow indaga: "o senhor falou antes de uma 'história das problemáticas'. O que isto quer dizer precisamente?". A resposta de Foucault (2004b) nos mostra a fina camada que singulariza o trabalho do pensamento: na problematização, trata-se de um movimento de separação.

O que distingue o pensamento é que ele é totalmente diferente do conjunto das representações implicadas em um comportamento; ele também é completamente diferente do campo das atitudes que podem determiná-lo. O pensamento não é o que se presentifica em uma conduta e Ihe dá um sentido; é, sobretudo, aquilo que permite tomar uma distância em relação a essa maneira de fazer ou de reagir, e tomá-la como objeto de pensamento e interrogá-la sobre seu sentido, suas condições e seus fins. (p. 231-232).

Foucault, portanto, torce o uso tradicional da noção de problema - um obstáculo que se apresentaria fora do pensamento -, para fazer dela efeito singular do próprio pensamento. Como diz Chevallier (2015, p. 299), a problematização é "a maneira na qual o pensamento se projeta adiante sob uma forma interrogativa, sem poder de modo algum antecipar o que advirá dela e das respostas que a história reterá. Ela é, então, da ordem da novidade" (p.308).

\section{DISPOSITIVO 3: ENCONTROS E CONVERSAS}

Quando falamos em estratégias, levamos a sério o que Michel Foucault (2008) aponta a respeito: "para que uma determinada relação de forças possa não somente se manter mas se acentuar, se estabilizar e ganhar terreno, é necessário que haja uma manobra" (p. 255). Assim pensada, nossa estratégia de ação habita os territórios de formação problematizando suas leis e normas identitárias, para deixar passar as forças imanentes, facultativas e perspectivadas, pela via de encontros e conversas.

O encontro entre escola básica e universidade se efetiva por meio de uma pesquisa que agencia filosofia da diferença (DELEUZE; GUATTARI, 2004b), análise institucional (LOURAU, 1993), políticas de cognição (KASTRUP, 1999), pesquisa-intervenção (ROCHA, 2012) e formação inventiva de professores (DIAS, 2012b). Não se trata de um encontro marcado por conversas fortuitas para atender a necessidades impostas pelos cursos de formação de professores, tampouco de uma investigação sobre a escola básica, mas de uma pesquisa-intervenção com a escola. Uma pesquisa que aproveita as brechas entre a macro e micropolítica e entra no território escolar com a perspectiva 
de analisar coletivamente e de intervir sobre/com o que acontece entre estudantes e professores da universidade e da escola básica.

Pesquisas do campo da representação, que separam sujeito e objeto, buscando a objetividade e a neutralidade científicas, não dão conta da complexidade e do dinamismo da instituição educativa. Já a pesquisa-intervenção, conforme a concebe Rocha (2012), intensifica a ruptura com modos tradicionais de investigar, além de ampliar as bases teórico-metodológicas das pesquisas participativas, surgindo como modo de agir de ordem micropolítica.

Nesta perspectiva, é preciso habitar o território da escola, abrir-se para os movimentos, as imprevisibilidades, com o olhar atento aos pequenos gestos, àquilo que não está dito ou está dito em tom muito baixo. A professora-coordenadora e as estudantes bolsistas da universidade vão para dentro da escola, assim como as professoras da escola passam a frequentar a universidade. O grupo de pesquisa conversa com professores e estudantes, funcionários, pais, diretores; sente na pele suas tramas e dramas; é afetado com os diversos acontecimentos de todos os dias. Tais estratégias são registradas em diários de campo.

Em trabalhos anteriores (DIAS, 2016), multiplicamos registros de diários, com suas tessituras fragmentárias. O diário é apreendido pela análise institucional como possibilidade de desnaturalizar o que acontece e criar outros sentidos para fazeres e dizeres (LOURAU, 1993). Não tem sentido próprio nem figurado, já que se faz implicado, remetendo às situações abordadas. O diário como método (ou o diário e o método) trabalha( $\mathrm{m})$ na tessitura das bordas, lá onde a forma deixa de ser o que foi em algum momento naturalizado. Fazer vibrar essas bordas em um processo de contágio, abrir o diário para suas intensidades, trabalhar mais nas misturas que o compõem e menos em uma (suposta) pureza parecem ser potentes indícios político-formativos para que um relato singular não se dissocie de sua face coletiva.

Cada fragmento é a expressão de uma ação que se constitui em práticas efetivas, abertas às intensidades e às diferenças. Trata-se de tomar o trabalho do diário longe do padrão para poder tratá-lo como próximo à alteridade, aos processos éticos, estéticos e políticos. Com isso, mostramos que escrever, fazer e dizer correspondem a uma política formativa pela qual se apreende uma dimensão experiencial, em exercícios concretos, e também uma dimensão expressiva que abre um entrelugar e um entretempo para forjar experiências modificadoras de si. Assim, a interrupção como sentido e a ruptura como forma nos forçam a pensar que os fragmentos de diário não são textos inacabados; abrem, antes, outra modalidade de acabamento: a que está em jogo na espera, na problematização e/ou em alguma afirmação irredutível de acolher o desconhecido sem o reter/deter. Nessa linha, nosso modo de trabalhar problematiza

o lugar do aluno-professor solucionador de problemas, tensionando os postulados hegemônicos da formação, como aquele que faz funcionar a máquina de propagação da informação e da explicação. O lugar comum da explicação comporta dois âmbitos indissociados. Um produz certo conforto no aprender. $\mathrm{O}$ aluno sente-se atendido com a explicação do mestre, produzindo um consenso. Outro âmbito, da explicação, freia o esforço do pensamento, pois, quando o professor explica, ao mesmo tempo que diz a resposta, ele forja no aluno a impossibilidade de pensar por si. Nessa perspectiva, a explicação que comporta a resposta embota o processo de invenção de problemas, muito importante para uma formação inventiva. (DIAS, 2011, p. 257). 
A proposta da pesquisa-intervenção é dar visibilidade às forças, àquilo que é potência de transformação. Por isso, optamos por realizar, com a escola básica, projetos desenvolvidos pelas bolsistas e supervisionados por professoras da escola. Supervisionar e orientar estes trabalhos afirma a singularidade de encontrar-se e conversar, como vemos nas palavras de uma professora parceira:

Fazer parte da supervisão requer orientar cada grupo sem direcionar, mas negociando e intervindo. A palavra seria observar sem pensar aprioristicamente o que funcionaria pela minha experiência como professora. Isso é tenso, mas fica guardado. Já vemos a importância do grau de abertura que o projeto requer. Junto com este grau de abertura, a biblioteca composta por ensaios, textos e filmes que lemos e levamos como questões nas reuniões é um capítulo à parte no projeto. Eles dialogam constantemente conosco e suas leituras não acabam quando o livro termina, ficam reverberando em nós, produzindo efeitos sonoros.

Um processo instituinte que marca como foi importante aprender, com Lourau (1993), que "a instituição não é uma coisa observável, mas uma dinâmica contraditória construindo-se na história e no tempo" (p.11). Nesta pesquisa-intervenção experimentamos o movimento constante em que forças instituídas lutam com forças instituintes. Ler, estudar, escrever, pensar, encontrar-se e conversar regularmente na escola, criar espaços de pesquisa, estabelecer reuniões periódicas com a direção, abertas aos professores, para discutir e analisar a escola básica, propor projetos com os alunos em que ocorre o deslocamento do "faça como eu" para o "faça comigo" (DIAS, 2011) são, decerto, forças que mexem com uma escola instituída para não pensar, para não se analisar, para nada inventar.

Vamos aprendendo, estudantes-professoras e professoras, que pesquisar, intervir, conhecer, transformar fazem parte do mesmo processo. Não há binarismos, mas problematizações que abrem para as multiplicidades e, ao mesmo tempo, para a singularização. A intervenção ocorre no grupo, na produção de outras subjetividades; desnaturaliza o que está dado, incomoda o instituído, provoca o pensamento a experimentar a autogestão (LOURAU, 1993), as práticas coletivas; em suma, a possibilidade de constituir o si e o mundo. A intervenção continua em nós, sempre em formação, como vemos expresso em diários de pesquisa:

Hoje resolvi fazer uma experiência nas minhas aulas da $2^{a}$ série. A ideia era deixar para trás as verdades fechadas, e entrar em sala sem expectativa, deixando fluir o acontecimento. Foi uma sensação estranha, com quase 30 anos de magistério, me sentir uma novata, entrando na sala pela primeira vez. Não sabia o que poderia acontecer, estava só aberta para o imprevisível. Experimentei a leveza, mas também um pouco de insegurança, pois embora afetada com as ideias novas, não sabia até que ponto estavam incorporadas. Queria experimentar "o faça comigo" e sair do "faça como eu", e estar no "entre" como propunha Rosimeri. Havia preparado a aula, mas não ensaiado direito como ensinou Deleuze. A técnica, copiei da Shirley que havia feito com os professores, no ano passado. Trouxe uma caixinha com frases dentro de envelopes coloridos. Como meu primeiro assunto era lluminismo aproveitei temas como liberdade, cidadania, igualdade e outros sobre relacionamentos, etc. Com os alunos em círculo, falei brevemente sobre a proposta: Uma bolinha vai passar de mão em mão, enquanto ouvem uma música, quando ela parar o aluno ou aluna virá até a mesa, vai pegar um envelope, ler e opinar sobre o tema. Perguntei se alguém poderia ficar responsável pela música de um celular. Na semana anterior havíamos discutido sobre o uso do celular em sala, mas disse brevemente que aquele era um outro uso, um uso coletivo, necessário para o desenvolvimento da aula. Foi interessante vê-los discutir um pouco sobre o som, resolvendo entre eles, sobre o melhor tipo de música. Estavam meio envergonhados, mas aos poucos foram se abrindo para o debate. Procurei ficar quieta, não opinar, mesmo quando a bolinha parava em mim. Numa das salas me questionaram por que eu não respondia. Disse que naquele jogo era importante eles falarem o 
que pensavam. Segurei-me para não dar nenhuma lição de moral, quando o tumulto se anunciava. Deixei acontecer, ou melhor, me deixei experimentar o acontecimento. Algumas vezes falava algo ou lançava uma questão só para provocar o debate. Uns 15 minutos antes de terminar a aula, pedi para comentarem sobre aquela experiência. Alguns não queriam. Houve um pouco de barulho. Falei então o quanto importavam as suas ideias e sensações, que elas precisavam ser registradas. Que agora precisavam do silêncio, quietude para ouvirem a si próprios, para poder pensar melhor e escrever. Foi muito bom experimentar o silêncio e a escrita dos alunos. Ninguém pediu para sair ou fez uso do seu celular... .(DIAS; PELUSO, UCHÔA, 2013, p. 10).

O eixo de intervenção da pesquisa se delineia quando fazemos o mergulho no plano implicacional, onde conhecer e fazer tornam-se inseparáveis. Acontece uma desnaturalização da escola, levando em conta o conjunto das condições da pesquisa e da instituição (DIAS, 2012a). Tensionamos o instituído com as ferramentas conceituais e as estratégias propostas pelos sentidos da problematização e da formação perspectivada pela invenção. Com isso, criamos uma política de trabalho, uma estilística, uma estética da existência (FOUCAULT, 1994c).

\section{CONSIDERAÇÕES FINAIS}

$\mathrm{Na}$ aula de 17 de fevereiro de 1982, Foucault (2004a, p.306) evoca o quanto, no presente, nos referimos à necessidade de construir uma "ética do eu", sem chegar a dar-lhe um conteúdo preciso. Parece-Ihe (e também a nós) que essa impossibilidade decorre do fato de o Ocidente ter conservado apenas dois modelos: o da epistrophé platônica, que aponta, via reminiscência, para um outro mundo saída (nihilista) para nossas decepções neste mundo - e o da exegese cristã, ininterrupta decifração voltada a vasculhar, em profundidade, uma alma sujeita a tentações - alma-sujeito à qual, com base na obediência e na culpa, se deve renunciar (neste mundo) para alcançar a salvação (no outro).

Além desses dois caminhos, resta-nos - Foucault o dissera em 6 de janeiro - a objetivação científico-tecnocrático-profissionalizada, cujos começos remontam a um "momento cartesiano" que cinde o plano epistemológico do plano ético: o sujeito pode agora conhecer sem que seu ser de sujeito precise ser transformado, bastando-lhe as regras formais de método e as qualificações pedagógicoculturais.

Quanto ao problema contemporâneo da formação, tanto os modelos platônico e cristão de conversão a si quanto a ausência de aspiração ética ligada ao momento cartesiano parecem veicular unicamente impasses: "os professores não são mais idealistas, é preciso reencantá-los"; "fascinados que estão com o dinheiro, carecem de dedicação, é necessário reorientá-los", "são mal formados, é indispensável fornecer-Ihes instrumentos metodológicos renovados" etc.

Não é difícil perceber que tanto a formação platônica como a cristã apontam a transcendências correlacionáveis a guias, leis, regulações especializadas. Prescindir do cuidado de si, por sua vez, implica aguardar pelo mais novo tecnocrata, pronto a tudo solucionar à base de técnicas e/ou de algum grau adicional na hierarquia das "certificações" pedagógicas.

Já o que Foucault (2004a, p.314) apelida "modelo do meio", ou seja, o cuidado de si helenístico-romano, poderia associar-se ao que, desde o início deste artigo, designamos como "formação inventiva". Tal formação aposta na construção coletiva de um "equipamento" (paraskeue) 
que nos faculte seja retornar a nós mesmos como porto seguro, seja construir a nós mesmos, durante toda a vida. A respeito dessa oscilação entre retorno e construção, ouçamos novamente a perguntaprovocação de Foucault (2004a): "Que círculo é esse, que circuito, que dobra é esta que devemos operar relativamente a algo que, contudo, não nos é dado, senão apenas prometido ao termo de nossa vida?" (p.302).

Em tais práticas e exercícios - pois é disso que se trata no "modelo do meio" - desaparecem os lamentos, pois há sempre algo a fazer: algo facultativo, não obrigatório, porém inevitavelmente voltado a engendrar um cotidiano libertário. E o que seria esse cotidiano? Ousamos propor que seria aquele que vê, na arte de constituir, hoje, uma ética do eu, "uma tarefa urgente, fundamental, politicamente indispensável, se for verdade que, afinal, não há outro ponto [...] de resistência ao poder político senão na relação de si para consigo" (FOUCAULT, 2004a, p.306).

\section{REFERÊNCIAS}

1. CHEVALLIER, Philippe. Que quer dizer fazer uma história das problematizações? Mnemosine. Rio de Janeiro, $\quad$ v. $11, \quad n^{\circ} \quad 2, \quad 2015, \quad$ p. 298-312. Disponível em: http://www.mnemosine.com.br/ojs/index.php/mnemosine/article/view/455/377 Acesso em 22 out 2017.

DELEUZE, Gilles. Proust e os signos. Rio de Janeiro: Forense Universitária, 2003.

DELEUZE, Gilles. O que é um dispositivo? In: DELEUZE, G. Dois regimes de loucos. Rio de Janeiro: Ed. 34, 2016. pp. 359-369.

4. DELEUZE, Gilles; GUATTARI, Felix. Mil Platôs: capitalismo e esquizofrenia. Vol. 1. Rio de Janeiro: Editora 34, 2004a.

5. DELEUZE, Gilles; GUATTARI, Felix. O que é filosofia? Rio de Janeiro: Ed. 34, 2004b.

6. DIAS, Rosimeri de Oliveira. Fragmentos de diário de campo, escrita e devir texto. In: CALLAI, Cris; RIBETTO, Anelice. Uma escrita acadêmica outra: ensaios, experiências e invenções. Rio de Janeiro: FAPERJ/Lamparina, 2016, p. 111-123.

7. DIAS, Rosimeri de Oliveira. Deslocamentos na formação de professores: aprendizagem de adultos, experiência e políticas cognitivas. Rio de Janeiro: Lamparina, 2011.

8. DIAS, Rosimeri de Oliveira. Produção da vida nos territórios escolares: entre universidade e escola básica. Psicol. Soc., Belo Horizonte, v. 24, n. spe, 2012a, p. 67-75. Disponível em http://www.scielo.br/scielo.php?script=sci_arttext\&pid=S010271822012000400011\&lng=pt\&nrm=iso Acesso em 01 ago 2019. http://dx.doi.org/10.1590/S0102-71822012000400011. 
9.

10. micropolítica e formação inventiva de professores. Mnemosine. Volume 9, $n^{\circ} 1$. Rio de Janeiro: UERJ, 2013, p224-237. http://www.mnemosine.com.br/ojs/index.php/mnemosine/article/view/283/pdf_266 Acesso em 11 out 2017.

11.

13. Paris: Gallimard, 1994b. Gallimard, 1994c. política Rio de Janeiro: Forense Universitária, 2004b. pp. 225-233

17. FOUCAULT, Michel. Sobre a história da sexualidade. In: FOUCAULT, M. Microfísica do poder. $26^{\mathrm{a}}$ ed. Rio de Janeiro: Graal, 2008. pp. 243-276. M. Ditos e escritos IX: genealogia da ética, subjetividade e sexualidade. Rio de Janeiro: Forense Universitária, 2014b, p. 214-237. KASTRUP, Virgínia. A invenção de si e do mundo: uma introdução do tempo e do coletivo no estudo da cognição. São Paulo: Papirus, 1999. 
23.

24.

\section{Oliveira. Formação inventiva de professores. Rio de Janeiro: Lamparina, 2012, p. 42-51.}

\section{Rosimeri de Oliveira Dias}

Professora Associada do Departamento de Educação e do Programa de Pós-Graduação em Educação Processos Formativos e Desigualdades Sociais da FFP/UERJ; Procientista/UERJ e Jovem Cientista FAPERJ.

\section{Heliana de Barros Conde Rodrigues}

Professora Associada do Instituto de Psicologia e do Programa de Pós-Graduação Políticas Públicas e Formação Humana da UERJ, Procientista UERJ.

\section{Como citar este documento:}

DIAS, Rosimeri de Oliveira; RODRIGUES, Heliana de Barros Conde. Deslocamentos, invenção e formação outra - em companhia de Foucault. Reflexão e Ação, Santa Cruz do Sul, v. 28, n. 3, p. 166180, $2020 . \quad$ aug. ISSN 1982-9949. Disponível em: <https://online.unisc.br/seer/index.php/reflex/article/view/14278>. Acesso em: doi:https://doi.org/10.17058/rea.v28i3.14278. 